\title{
CORRESPONDENCE
}

Chronic fatigue syndrome: commenting on the commentaries

I have good cause to respect the work of Professor Fulford, Professor Kendell and Dr White. Professor Fulford is pioneering the application of linguistic philosophy to psychiatry, a project which has my wholehearted support. I have learned much from Professor Kendell's incisive writings, including The Role of Diagnosis in Psychiatry (Kendell, 1975). Dr White, in addition to his committed work in helping patients with chronic fatigue syndrome (CFS)/ myalgic encephalomyelitis (ME) to improve or recover has, with his colleagues, produced a convincing demonstration that Epstein-Barr virus infection is sometimes a precursor of CFS/ME (White et al, 1995).

Respect, however, does not always lead to agreement. In the present case, I have much agreement with Fulford but less with Kendell and White.

Fulford Fulford's (2002) commentary, although critical on some points in my paper (Sykes, 2002), provides strong support for my two central theses. First, given that in the current situation, all illnesses are classed as either physical or mental, CFS/ME should generally be classed as a physical illness. Second, a better way of drawing the distinction between physical and mental illness needs to be devised and widely introduced.

On the first point, Fulford is in agreement that, in the present situation, CFS/ME should, in general, be classed as a physical illness, although the grounds he gives for this conclusion are different from mine. He argues that the distinction between physical and mental illness should be drawn at the level of symptoms and on this basis, because of the bodily symptoms of CFS/ME, it should generally be classed as a physical illness.

Fulford and I both agree that the alleged psychological causation of CFS/ME is not a good ground for classifying it as a mental illness. The reason I give is that CFS/ME does not have a psychological cause. The reason Fulford gives is that psychological causation is not an acceptable criterion for mental illness. His argument thus complements mine and supports the same conclusion.

In the September 2002 issue of APT, R.E. Kendell, K.W.M. Fulford and Peter D. White each wrote a commentary on a paper by Richard Sykes addressing the classification of chronic fatigue syndrome as a physical or mental illness. Here we publish Dr Sykes's response to these commentaries.
Fulford also gives support to my second thesis. He thinks that the distinction between physical and mental illness can be drawn at the symptomatic level. Physical disorders are those in which the symptoms involve bodily functions; mental disorders involve the 'higher' mental functions. This proposal is tantamount to the suggestion that the distinction should be redrawn, for this is not the way in which it is currently defined. Fulford's way of making the distinction would mean, for example, that somatoform disorders would no longer count as mental disorders.

Kendell and White There is not the space to deal in detail with Kendell's (2002) and White's (2002) arguments. I will just make a few observations.

As regards the classification of CFS/ME, neither Kendell nor White addresses the crucial question that is posed by my paper. This is, 'Given that currently all illnesses are classified as physical or as mental ones, how should CFS/ME be classified?' Although criticising my view that, in this situation, CFS/ME should be classified as a physical illness, neither of them is prepared to advocate the only alternative, that it should be classified as a mental illness. White, for example, says that 'to regard CFS as a physical disease would be as great an error as to regard it as a psychological illness'.

In failing to address this crucial question, they have failed to address the situation faced by patients with CFS/ME whose illness will be classified in the real situations in which they are placed.

White states that 'the most consistent findings regarding the aetiology of CFS are "psychosocial"". But both the findings and their significance are strongly debated. In reality, research findings give no clear answers as to how CFS/ME should be classified.

Kendell appears to think that my arguments are of so little worth that he 'is left with the strong impression that any argument will do as long as it produces the desired conclusion'. But scorn is not a proper substitute for rational argument and his arguments against the points he mentions are either absent, irrelevant or poor.

Kendell gives no reason for not accepting the principle that 'Adopting a conservative strategy, psychological causation should not be imputed in difficult cases where there is no widespread agreement'.

Second, his comment that psychological causation is not a criterion of mental illness in general is true but it is not relevant. 
Third, he thinks that patients with CFS/ME do not experience it as a physical illness but merely believe that it is a physical illness. But in my view, patients do experience CFS/ME as a physical illness - as something like a very nasty attack of influenza which has never gone away. And even if it were true that patients with the syndrome merely believe that they have a physical illness, is this to be considered worthless?

Kendell is on difficult ground here. My hope is that he does not actually think that these and similar beliefs of intelligent and self-aware patients are worthless, despite the context in which his remarks appear. He must be aware, though, that such attitudes are not unknown in discussions about CFS/ $\mathrm{ME}$ and that they have created much antagonism. Such attitudes are out of step with the contemporary recognition of the expertise of 'the expert patient'. They are substantial barriers to progress and have done nothing to advance the standing of psychiatry in this field.

As regards the distinction between physical and mental illness, some psychiatrists today would have us believe that any distinction between body and mind, and with it any distinction between mental and physical factors, is just a relic of Cartesian dualism and is incompatible with a modern biopsychosocial model.

But this, as Fulford forcibly points out, is 'plainly nonsense. The "biopsycho-" part of the model directly depends on the body/mind distinction'. The reality is that the distinction between mind and body, between mental and physical factors, is a fundamental one which has not yet been replaced. The difficulties in drawing the distinction precisely cannot be disposed of simply by declaring the distinction out of date and ignoring the difficulties.

\section{Final comments}

The misperception of CFS/ME as a mental illness or as generally due to psychological problems, has led to much mistreatment of patients in the National Health Service and to much unnecessary suffering. This is well documented in the recent Governmentcommissioned report (Department of Health, 2002).
At Westcare UK, we have specialised in providing psychological help to patients with CFS/ME for the past 13 years. In our view, in the current situation, CFS/ME is generally best classified as a physical illness, which like other physical illnesses has psychological and social dimensions (Sykes \& Campion, 2002a,b). This view is supported by a large majority of patients. Is it now time to take this shared perspective seriously?

More generally, confusion about basic concepts associated with illnesses that are currently called 'mental' illnesses creates unnecessary problems. The task of finding and agreeing a clear conceptual structure within which to describe and classify these illnesses is both important and urgent. My hope is that this task will be undertaken soon in an open, collaborative and cooperative way, with contributors from many fields. Linguistic philosophy, as Fulford (1990) has demonstrated, could have a valuable contribution to make.

Department of Health (2002) Report of the CFS/ME Working Group. Report to the Chief Medical Officer of an Independent Working Group. Leeds: Department of Health.

Fulford, K. W. (1990) Philosophy and medicine: the Oxford connection. British Journal of Psychiatry, 157, 111-115.

- (2002) Commentary on 'Physical or mental? A perspective on chronic fatigue syndrome'. Advances in Psychiatric Treatment, 8, 359-363.

Kendell, R. E. (1975) The Role of Diagnosis in Psychiatry. Oxford: Blackwell.

- (2002) Commentary on 'Physical or mental? A perspective on chronic fatigue syndrome'. Advances in Psychiatric Treatment, 8, 358-359.

Sykes, R. D. (2002) Physical or mental? A perspective on chronic fatigue syndrome. Advances in Psychiatric Treatment, 8, 351-365.

- \& Campion, P. (2002a) The Physical and the Mental in Chronic Fatigue Syndrome/ME. Principles of Psychological Help. Bristol: Westcare UK.

- \& - (2002b) Chronic Fatigue Syndrome/ME. Trusting Patients' Perceptions of a Multi-dimensional Physical Illness. Bristol: Westcare UK.

White, P. (2002) Commentary on 'Physical or mental? A perspective on chronic fatigue syndrome'. Advances in Psychiatric Treatment, 8, 363-365.

-, Thomas, J., Amess, J., et al (1995). The existence of a fatigue syndrome after glandular fever. Psychological Medicine, 25, 907-916.

Richard Sykes Director, Westcare UK, 155 Whiteladies Road, Clifton, Bristol BS8 2RF, UK. 